\title{
Биполярная остаточная фотопроводимость в гетероструктурах HgTe/CdHgTe (013) с двойными квантовыми ямами
}

\author{
(C) К.Е. Спирин ${ }^{1}$, Д.М. Гапонова ${ }^{1}$, К.В. Маремьянин ${ }^{1}$, В.В. Румянцев ${ }^{1}$, \\ В.И. Гавриленко ${ }^{1}$, Н.Н. Михайлов ${ }^{2}$, С.А. Дворецкий ${ }^{2}$ \\ ${ }^{1}$ Институт фризики микроструктур Российской академии наук, ГСП-105, \\ 603950 Нижний Новгород, Россия \\ ${ }^{2}$ Институт ффизики полупроводников им. А.В. Ржанова Сибирского отделения Российской академии наук, \\ 630090 Новосибирск, Россия \\ E-mail: spirink@ipmras.ru
}

(Получена 25 апреля 2018 г. Принята к печати 7 мая 2018 г.)

Исследовались эффекты остаточной фотопроводимости в гетероструктурах $\mathrm{HgTe} / \mathrm{CdHgTe}(013)$ с двойными квантовыми ямами при $T=4.2 \mathrm{~K}$. Показано, что остаточная фотопроводимость в данной системе имеет биполярный характер, т.е. присутствует как положительная, так и отрицательная остаточная фотопроводимость в зависимости от длины волны подсветки.

DOI: 10.21883/FTP.2018.12.46761.41

\section{1. Введение}

Неослабевающий интерес исследователей к гетероструктурам на основе $\mathrm{HgTe} / \mathrm{CdHgTe}$ связан с рядом замечательных свойств, которыми обладает данная система. Всплеск такого интереса обусловлен появлением работ [1-3], в которых, в частности, было теоретически показано и экспериментально продемонстрировано существование фазы двумерного (2D) топологического изолятора (ТИ) в квантовых ямах (КЯ) $\mathrm{HgTe} / \mathrm{CdHgTe}$ с инвертированной зонной структурой. При исследовании зонной структуры КЯ важно иметь возможность изменять концентрацию носителей заряда и уровень Ферми в процессе эксперимента. При магнитотранспортных измерениях это обычно достигается изготовлением образцов в виде холловских мостиков с затвором. Для магнитооптических измерений требуется изготовление полупрозрачных затворов большой площади, что является, зачастую, технологически сложной задачей (см. [4]). Другим методом изменения концентрации носителей в КЯ во время низкотемпературного эксперимента является использование эффекта остаточной фотопроводимости (ОФП) (см., например, [5]). Ранее мы неоднократно использовали эффект положительной остаточной фотопроводимости в гетероструктурах $\mathrm{HgTe} / \mathrm{CdHgTe} \mathrm{c}$ одиночной квантовой ямой (КЯ) (см., например, [6]). В настоящей работе сообщается о первых наблюдениях эффекта биполярной ОФП в гетероструктурах $\mathrm{HgTe} / \mathrm{CdHgTe} \mathrm{c} \mathrm{двойными} \mathrm{КЯ.} \mathrm{Выполнены} \mathrm{спектральные}$ исследования, продемонстрировавшие возможность последовательного изменения концентрации как в сторону увеличения, так и в сторону уменьшения и даже смены типа проводимости.

\section{2. Исследуемые образцы и методика эксперимента}

Исследуемые в настоящей работе образцы с двойными КЯ были выращены методом молекуярно-лучевой эпи- таксии на подложке GaAs (013) на метаморфном буфере $\mathrm{CdTe}$ Параметры слоев для всех исследуемых образцов представлены в таблице. Структуры специально не легировались, при охлаждении в них наблюдалась темновая концентрация дырок $\sim 7-12 \cdot 10^{10} \mathrm{~cm}^{-2}$, обусловленная, очевидно, ионизацией нейтральных акцепторов (предположительно вакансий ртути) в прилегающих к КЯ барьерных слоях [7].

При исследовании остаточной фотопроводимости образцы размещались в гелиевом криостате, все измерения проводились при температуре $4.2 \mathrm{~K}$. При исследовании спектров ОФП к образцу квадратной формы, размерами $5 \times 5$ мм делались два полосковых омических контакта по краям. Через образец пропускался постоянный ток 1 мкА. С помощью гибкого многожильного световода образец освещался монохроматическим излучением с выхода решеточного монохроматора МДР-23 [5], источником излучения являлась кварцевая лампа накаливания. Измерялось изменение сопротивления образца в зависимости от длины волны падающего излучения. Вследствие конструктивных особенностей монохроматора непрерывную запись спектра при развертке длины волны излучения можно было осуществлять только от меньших длин волн к большим. Поэтому для регистрации ОФП при проходе от больших длин волн к меньшим использовался поточечный метод измерений. При измерении транспортных характеристик к образцу делалось четыре омических контакта, измерения проводились в геометрии Ван дер Пау.

\section{3. Результаты и обсуждение}

На рис. 1 представлены спектры остаточной ФП трех исследуемых образцов. Символы на рис. $1, b$ соответствуют второму методу регистрации ОФП при движении от больших длин волн к меньшим. Хорошее согласие двух методов измерений свидетельствует о том, что в каждый конкретный момент времени сопротивление 
Конструкция и структурные параметры трех исследуемых образцов $\mathrm{HgTe} / \mathrm{CdHgTe}$

\begin{tabular}{|c|c|c|c|c|c|c|}
\hline \multirow{2}{*}{ Слой } & \multicolumn{3}{|c|}{ Состав слоя $\mathrm{Cd}_{x} \mathrm{Hg}_{1-x} \mathrm{Te}$} & \multicolumn{3}{|c|}{ Толщина слоя (нм) } \\
\hline & № 150217 & № 151225 & № 160122 & № 150217 & № 151225 & № 160122 \\
\hline $\begin{array}{l}\text { Покрывающий слой } \mathrm{CdTe} \\
\text { Барьерный слой } \mathrm{Cd}_{x} \mathrm{Hg}_{1-x} \mathrm{Te} \\
\text { Квантовая яма } \mathrm{HdTe} \\
\text { Барьерный слой } \mathrm{Cd}_{x} \mathrm{Hg}_{1-x} \mathrm{Te} \\
\text { Квантовая яма } \mathrm{HdTe} \\
\text { Метаморфный буфер CdTe } \\
\text { Метаморфный буфер } \mathrm{ZnTe} \\
\text { Подложка }\end{array}$ & $\begin{array}{l}x=0.64 \\
x=0.64\end{array}$ & $\begin{array}{c}x=1 \\
x=0.58 \\
x=0 \\
x=0.58 \\
x=0 \\
x=1 \\
\text { ZnTe } \\
\text { GaAs }(013)\end{array}$ & $\begin{array}{l}x=0.43 \\
x=0.43\end{array}$ & $\begin{array}{l}4.5 \\
4.5\end{array}$ & $\begin{array}{c}40 \\
30 \\
7.5 \\
30 \\
7.5 \\
5-6 \mathrm{MKм} \\
30 \mathrm{HM} \\
400 \text { мКм }\end{array}$ & $\begin{array}{l}8 \\
8\end{array}$ \\
\hline
\end{tabular}

образца определяется только длиной волны падающего излучения (кроме самого коротковолнового участка спектра, см. далее), не зависит от предыдущих состояний образца и остается неизменным после выключения подсветки.

Максимум сопротивления, наблюдаемый в спектрах ОФП исследуемых образцов при $\lambda \approx 350$ нм, соответствует процессу изменения типа проводимости образца. В этой области спектра интенсивность излучения кварцевой лампы накаливания мала и наблюдаемое изменение сопротивления соответствует зависимости не от длины волны, а от времени. Изначально, после охлаждения в КЯ имеется некоторая остаточная концентрация носителей $p$-типа (см. рис. 2). После освещения образца квантами с высокой энергией в покрывающем слое CdTe происходит генерация электронно-дырочных пар за счет

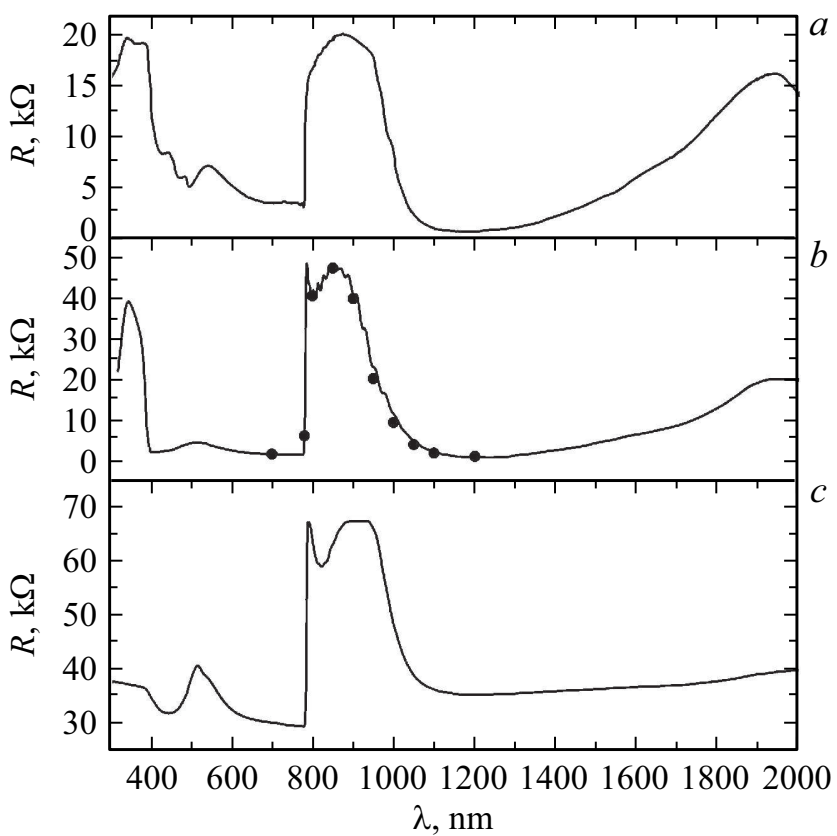

Pис. 1. Спектры остаточной проводимости для исследуемых образцов HgTe/CdHgTe: $a$ - № 160122, $b$ - № 151225, $c$ - № 150207. Символы на спектре $b$ соответствуют второму методу измерения ОФП.

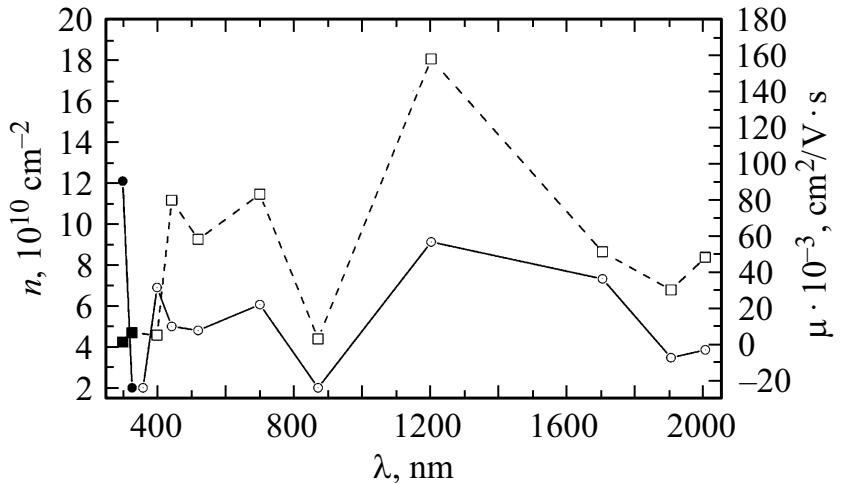

Рис. 2. Значения концентрации (ось слева, круглые символы) и подвижности (ось справа, квадратные символы) для образца № 160122 в зависимости от длины волны падающего излучения. Заполненные символы соответствуют дырочному типу проводимости образца, пустые - электронному типу.

межзонных переходов. Под действием встроенного электрического поля, направленного от подложки в сторону поверхности структуры, происходит пространственное разделение носителей заряда и увлечение электронов к квантовой яме, что приводит к смене типа проводимости в КЯ на электронный (рис. 2). Следует отметить, что о наличии в структурах $\mathrm{HgTe} / \mathrm{CdHgTe}$ с двойной КЯ сильного встроенного электрического поля сообщалось в работах $[8,9]$. Например, в работе [9] приводятся результаты эксперимента, показывающего, что приложение к затвору на поверхности структуры положительного напряжения $\approx 3$ В приводит к выравниванию встроенного поля. Таким образом, можно сделать вывод о направлении вектора $\mathbf{E}$ от подложки к поверхности структуры. Оценочная величина встроенного электрического поля в районе квантовых ям составляет порядка нескольких десятков кВ/см.

На рис. 3 приведена схема перераспределения носителей в структуре под действием падающего излучения. Как видно из рис. 2, в интервале длин 400-700 нм концентрация электронов в КЯ находится на уровне $\sim 5 \cdot 10^{10} \mathrm{~cm}^{-2}$, что является следствием нескольких конкурирующих процессов. До длины волны $\lambda \approx 780$ нм, 


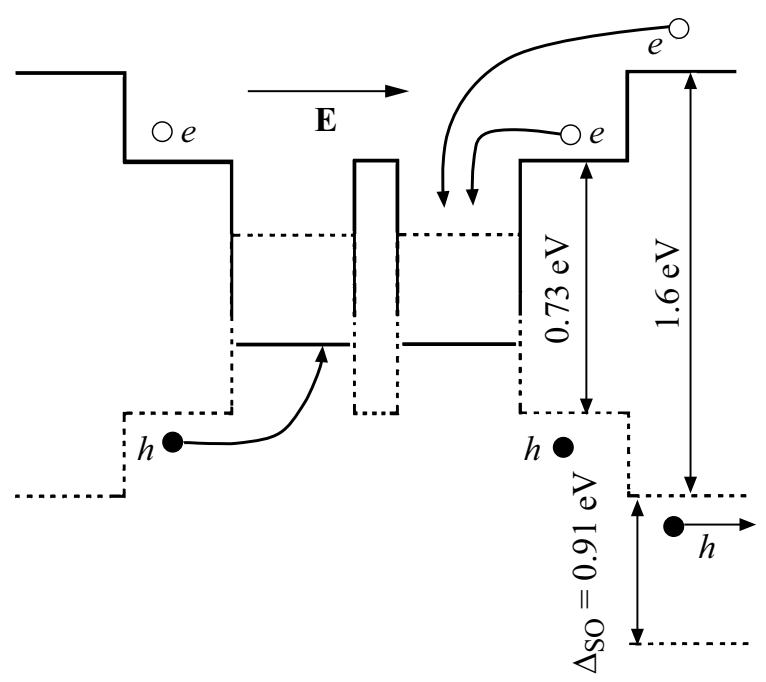

Рис. 3. Схема перераспределения носителей внутри структуры под действием падающего излучения.

соответствующей ширине запрещенной зоны в $\mathrm{CdTe}$, межзонная генерация электронно-дырочных пар происходит во всех слоях структуры, при этом, как видно из рис. 2, в КЯ сохраняется электронный тип проводимости. Помимо уже упомянутого механизма увлечения электронов К КЯ встроенным электрическим полем (роль которого, очевидно, уменьшается при смене типа проводимости в КЯ с $p$ на $n$ ) это может быть связано с большей подвижностью электронов, которые могут диффундировать к КЯ и против силы электрического поля. Дырки, напротив, при низкой температуре должны захватываться на ловушки, в роли которых могут выступать вакансии ртути - двойные акцепторы, обусловливающие исходный $p$-тип проводимости структуры [7]. Здесь следует отметить особенность в виде широкого пика сопротивления (и локального минимума электронной концентрации), наблюдаемую во всех трех образцах в области $\lambda \approx 520$ нм. Соответствующая энергия кванта 2.4 эВ близка к сумме ширины запрещенной зоны (1.6 эВ) и энергии спинового расщепления в валентной зоне $\left(\Delta_{\mathrm{SO}}=0.91\right.$ эВ $)$ и связывается с прохождением потолка спин-отщепленной подзоны дырок [10]. Резонансный характер особенности указывает на фотовозбуждение некоего локализованного центра, связанного со спин-отщепленной зоной дырок, приводящее к генерации высокоэнергетичных дырок, которые достигают КЯ, уменьшая тем самым концентрацию электронов в последней.

Резкое возрастание сопротивления при достижении длины волны $\lambda \approx 780 \mathrm{Hм}(1.6$ эВ), соответствующей ширине запрещенной зоны $\mathrm{CdTe}$, означающее фактически переход образцов в изолирующее состояние (см. рис. $1, b, c)$, сохраняющееся вплоть до длины волны 950 нм, требует особого осмысления. Энергии квантов излучения в этом участке спектра заметно превышают как величины ширины запрещенной зоны в барьерных слоях исследуемых образцов ( 0.73 эВ), так и энергии спин-орбитального расщепления во всех слоях структуры $(0.91-0.98$ эВ). Таким образом, оказывается, что несмотря на продолжающуюся генерацию сравнительно высокоэнергетичных электронов на межзонных переходах в барьерных слоях $\left(E_{\text {kin }} \sim 0.8\right.$ эВ, так как эффективная масса у электронов много меньше, чем у дырок, им „достается“" почти вся разница между энергией кванта и шириной запрещенной зоны), динамическое равновесие смещается „в пользу“ дырок, процесс генерации которых выключается на длине волны $\sim 0.95$ мкм $(\sim 1.3$ эВ $)$ (см. рис. 1). Так как соответствующая энергия кванта не соизмерима ни с одной характерной энергией на зонной схеме структуры (рис. 3), остается заключить, что имеют место переходы с достаточно широкого (по энергетической шкале) ансамбля глубоких центров (расположенных в барьерных слоях $\mathrm{CdHgTe),} \mathrm{которые}$ могут начинаться и при $\hbar \omega>1.6$ эВ, но „шунтируются“ в этой области межзонными переходами в CdTe. Такие переходы с центров „в глубине“ валентной зоны на дно зоны проводимости $\mathrm{CdHgTe} \mathrm{приводят} \mathrm{к} \mathrm{возникновению}$ высокоэнергетичных дырок, которые диффундируют и достигают КЯ HgTe. При дальнейшем увеличении длины волны более 1100 нм такие переходы „выключаются“ и генерируемые на межзонных переходах в CdHgTe горячие электроны вновь сдвигают динамическое равновесие в сторону $n$-типа проводимости в КЯ. При дальнейшем росте длины волны энергия фотоэлектронов в КЯ уменьшается, что приводит к постепенному падению концентрации электронов в КЯ.

Работа выполнена в рамках выполнения государственного задания ИФМ РАН, тема 0035-2014-0201, при частичной поддержке РФФИ (№ 16-02-00672). Характеризация и уточнение параметров структур выполнены при поддержке гранта Президента Российской Федерации для государственной поддержки молодых российских ученых — кандидатов наук МК-4399.2018.2. В работе использовано оборудование ЦКП ИФМ РАН.

\section{Список литературы}

[1] C.L. Kane, E.J. Mele. Phys. Rev. Lett., 95, 146802 (2005),

[2] B.A. Bernevig, T.L. Hughes, S.C. Zhang. Science, 314, 1757 (2006).

[3] M. Konig, S. Wiedmann, C. Brune, A. Roth, H. Buhmann, L.W. Molenkamp, X.-L. Qi, S.-C. Zhang. Science, 318, 766 (2007).

[4] M. Schultz, U. Merkt, A. Sonntag, U. Rössler, R. Winkler, T. Colin, P. Helgesen, T. Skauli, S. Løvold. Phys. Rev. B, 57, 14772 (1998).

[5] В.Я. Алешкин, В.И. Гавриленко, Д.М. Гапонова, А.В. Иконников, К.В. Маремьянин, С.В. Морозов, Ю.Г. Садофьев, S.R. Johnson, Y.-H. Yang. ФТП, 39 (1), 30 (2005).

[6] А.В. Иконников, А.А. Ластовкин, К.Е. Спирин и др. Письма ЖЭТФ, 92 (11-12), 837 (2010).

[7] V.V. Rumyantsev, D.V. Kozlov, S.V. Morozov, M.A. Fadeev, A.M. Kadykov, F. Teppe, V.S. Varavin, M.V. Yakushev, N.N. Mikhailov, S.A. Dvoretskii, V.I. Gavrilenko. Semicond. Sci. Technol., 32, 095007 (2017). 
[8] А.В. Иконников, Л.С. Бовкун, В.Я. Алешкин, М. Orlita, B.A. Piot, M. Potemski, C.C. Криштопенко, С.А. Дворецкий, Н.Н. Михайлов, В.И. Гавриленко. Тр. ХХІІ Межсдунар. симп. „Нанофизика и наноэлектроника“ (12-15 марта 2018 г., Нижний Новгород) т. 2, с. 635.

[9] М.В. Якунин, С.С. Криштопенко, С.М. Подгорных, M.P. Попов, В.Н. Неверов, F. Teppe, B. Jouault, W. Desrat, С.А. Дворецкий, Н.Н. Михайлов. Тр. ХХІІ Межсуунар. симп. Нанофизика и наноэлектроника“ (12-15 марта 2018 г., Нижний Новгород) т. 2, с. 843.

[10] K.H. Yoo, R.L. Aggarwal, L.R. RamMohan, O.K. Wu. J. Vac. Sci. Technol. A, 8, 1194 (1990).

Редактор А.Н. Смирнов

\section{Bipolar persistent photoconductivity effects in $\mathrm{HgTe} / \mathrm{CdHgTe}(013)$ double quantum well heterostructures}

K.E. Spirin', D.M. Gaponova ${ }^{1}$, K.V. Marem,yanin ${ }^{1}$, V.V. Rumyantsev ${ }^{1}$, V.I. Gavrilenko ${ }^{1}$, N.N. Mikhailov ${ }^{2}$, S.A. Dvoretsky ${ }^{2}$

${ }^{1}$ Institute for Physics of Microstructures, Russian Academy of Sciences, 603950 Nizhny Novgorod, Russia

${ }^{2}$ Rzhanov Institute of Semiconductor Physics,

Siberian Branch of Russian Academy of Sciences, 630090 Novosibirsk, Russia

Abstract Persistent photoconductivity effects in $\mathrm{HgTe} /$ CdHgTe (013) heterostructures with double quantum wells has been investigated at $T=4.2 \mathrm{~K}$. The bipolar character of persistent photoconductivity in this system, i.e. both positive and negative persistent photoconductivity depending on the wavelength of illumination has been shown. 